\title{
TRADICIÓN Y ANTITRADICIÓN EN NICANOR PARRA
}

\author{
TRADITION AND ANTITRADITION IN NICANOR PARRA
}

\section{HUGO MONTES BRUNET*}

\section{RESUMEN}

Los antipoemas de Nicanor Parra tienen antecedentes clarísimos en varios escritores clásicos, como el Arcipreste de Hita y Francisco de Quevedo. Estos antecedentes permiten vincular la antipoesía con una tradición más que centenaria. Los poemas, en cambio, se alejan de tal tradición y paradójicamente rompen con lo tradicional; son desde este punto de vista antitradicionales.

Palabras clave: Poemas-antipoemas, tradición-antitradición, libertad y romanticismo, feísmo y belleza.

\section{ABSTRACT}

The antipoems of Nicanor Parra have a clear precedent in several classical writers such as Arcipreste de Hita and Francisco de Quevedo. This allows us to link antipoetry with a tradition that goes back more than a century. The poems, on the other hand, move away from the tradition and paradoxically break with it; they are from this perspective, antitraditional.

Key words: Poems-antipoems, tradition-antitradition, freedom and romanticism, ugliness and beauty.

Recibido: 15.05.14. Aceptado: 04.07.14.

* Doctor en Filología Románica (Freiburg Br.). Catedrático emérito en las Universidades de Chile y Católica de Chile. Premio Nacional de Ciencias de la Educación. Profesor invitado en las Universidades de Notre Dame, Costa Rica y Freiburg Br. Correo: cgonzalez@colegiosdiaconales.cl 

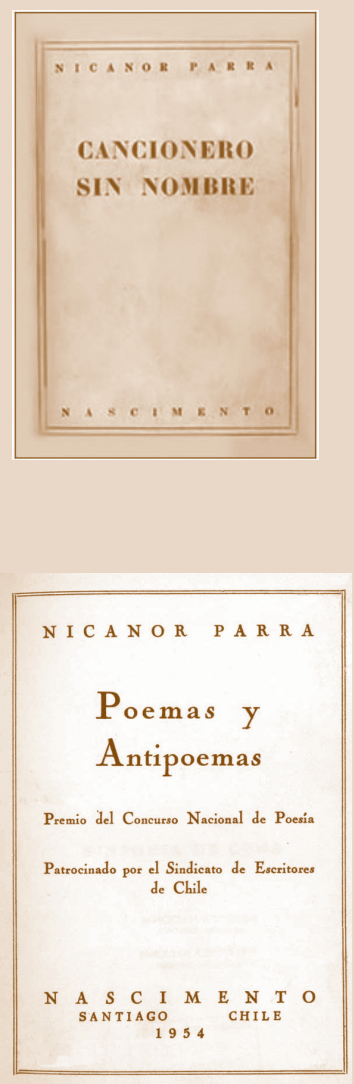

$\mathrm{L}$

AS CIFRAS SON CLARAS. Nicanor Parra cumplirá en septiembre de 2014 cien años. Lo que no cuadra es que un hombre centenario sea creador y no repetidor; que no parezca fatigado, sino cada día más entusiasta, jovial y entretenido. No le viene la palabra viejo, ni menos la palabra anciano. La suya es vida de permanente renovación.

Empezó a escribir desde su adolescencia. En 1954 hay una especie de bisagra en su obra. Antes y después del libro de ese año, puede hablarse de prehistoria y de historia, término acuñado por Niall Binns en la Introducción al primer tomo de las Obras completas de Parra (2006). La prehistoria tiene textos de búsqueda. Cancionero sin nombre, de 1937, es un poemario menor de sabor lorqueano que sin embargo mereció el Premio Municipal de Poesía. En 1952 publica Quebrantahuesos, donde se deja atrás la influencia de García Lorca y la presencia inevitable de Neruda y Huidobro. Es obra personal a la vez que semicolectiva, con el apoyo de Enrique Lihn y Jodorowsky, entre otros. Afanes de cuentista y de autor de ensayos también quedan atrás.

Reparemos en el título Poemas y antipoemas, el libro de 1954. No sólo antipoemas, también poemas. El "anti", únicamente para determinados textos. La diferencia es tajante. Los poemas, al menos los del libro recién indicado, obedecen a una métrica regular y a rimas asonantes. Se está ante una suerte de romancero tradicional. Así "Hay un día feliz", "Es olvido" y "Se canta al mar", de los que transcribimos los versos iniciales:

A recorrer me dediqué esta tarde

Las solitarias calles de mi aldea

Acompañado por el buen crepúsculo

Que es el único amigo que me queda.

Todo está como entonces, el otoño

Y su difusa lámpara de niebla, sólo que el tiempo lo ha invadido todo

con su pálido manto de tristeza. (2006: 12)

Juro que no recuerdo ni su nombre, Mas moriré llamándola María, No por simple capricho de poeta:

Por su aspecto de plaza de provincia. ¡Tiempos aquellos! Yo un espantapájaros, Ella una joven pálida y sombría.

$\mathrm{Al}$ volver una tarde del Liceo

Supe de su muerte inmerecida... (2006: 15) 
Nada podrá apartar de mi memoria

La luz de aquella misteriosa lámpara,

$\mathrm{Ni}$ el resultado que en mis ojos tuvo

Ni la impresión que me dejó en el alma.

Todo lo puede el tiempo, sin embargo

Creo que ni la muerte ha de borrarla.

Voy a explicarme aquí, si me permiten,

Con el eco mejor de mi garganta. (2006: 17)

"Sinfonía de cuna", "Catalina Parra", "Discursos en el cielo" y "San Antonio", del mismo libro, mantienen las asonancias en los versos pares. Añaden, no obstante, manifestaciones propias de la antipoesía, como el humor, la ironía y una fuerte crítica al cura lujurioso y simoníaco.

Años más adelante, en 1967, Nicanor publicó el libro Canciones rusas. Estamos en el apogeo de la antipoesía, apenas dos años antes de la aparición de Obra gruesa. Sin embargo, en medio de "Manifiesto" y "Cordero pascual" leemos "Aromos", sin visos de antipoesía. "Aromos" es un texto neorromántico y delicado, en el marco de árboles en flor y con el tema eterno del amor no correspondido. La impronta parriana, no obstante, es evidente, por ejemplo en frases hechas (imagínate tú, me dispararon a boca de jarro, nada que ver). Vale la pena transcribirlo.

Paseando hace años

Por una calle de aromos en flor

Supe por un amigo bien informado

Que acabas de contraer matrimonio.

Contesté que por cierto

Que yo nada tenía que ver en el asunto.

Pero a pesar de que nunca te amé

-Eso lo sabes tú mejor que yo-

Cada vez que florecen los aromos

-Imagínate tú-

Siento la misma cosa que sentí

Cuando me dispararon a boca de jarro

La noticia bastante desoladora

De que te habías casado con otro. (2006: 162)

Es una especie de vuelta atrás en el camino hacia la antipoesía. La bisagra del libro de 1954 parece no ser tan clara como dijimos. El antes y después no se respetan, ya que es posible encontrar un texto puramente poético en 
medio de plena antipoesía. Valga esto como una llamada de atención a cánones más aparentes que reales en el complejo y desconcertante quehacer literario de nuestro autor.

La llamada vale de modo particular a propósito del título del presente artículo: "Tradición y antitradición". ¿Qué es tradicional y qué antitradicional en Parra? Es fácil decir que la ruptura con la tradición ocurre sólo en los antipoemas. A la inversa, tradicionales serían los poemas, no importa si anteriores o posteriores a 1954. Pero cabe dudar de las respuestas muy fáciles. La duda se justifica a la luz de lecturas universales bien conocidas desde el Romanticismo hasta hoy.

Empezamos este excurso con Víctor Hugo y su Manifiesto romántico (1971), de 1827, fecha del estreno de Cromwell. Recuerda Víctor Hugo que el cristianismo lleva la poesía a la verdad. Y añade que en la creación no todo es hermoso, que "lo feo existe al lado de lo bello, lo deforme cerca de lo gracioso, lo grotesco en el reverso de lo sublime, el mal con el bien, la sombra con la luz". Invita a descansar de lo hermoso. De hecho al parecer de Víctor Hugo, actualmente hay un predominio de lo grotesco sobre lo sublime.

Esta apertura romántica abrió las puertas a los poetas franceses de la segunda mitad del siglo XIX hacia el "feísmo". Ya el título del principal poemario de Baudelaire es claro: Las flores del mal. De él basta recordar el comienzo del poema "Una carroña":
Alma mía, recógete y recuerda el objeto que hemos visto esta mañana al volver de una senda, un infame esqueleto sobre la tierra lozana.
Levantando las piernas como una mujer lúbrica, ardiente y sudando veneno, impudoroso abría, de una manera única, su vientre de emanaciones lleno'. ${ }^{1}$ (1961:34)

El eslabón más importante de esta cadena posromántica lo constituye Rimbaud. Leamos su soneto "Venus Anadyomène", traducido al español:

Como en un ataúd verde de hojalata, una cabeza de mujer con cabellos oscuros fuertemente empomados

\footnotetext{
${ }^{1}$ Traducción propia.
} 
emerge de una vieja tina de baño, lenta y torpemente, con carencias muy mal remendadas;

después el cuello graso y gris, los largos omóplatos que sobresalen; la espalda corta que entra y sale, luego las redondeces de los riñones que parecen tomar el vuelo; la grasa bajo la piel semeja hojas lisas.

La espina dorsal es casi roja, y el conjunto tiene un sabor extrañamente horrible, se notan sobre todo singularidades que había que ver con lupa...

Los riñones tienen grabadas dos palabras: Clara Venus -todo este cuerpo remueve y remata amplia grupa repugnantemente bella en una úlcera en el ano. (1980: 222)

Reparemos en el título "Venus Anadyomène”, evocador de la belleza más sublime de la antigüedad greco-romana. Tanta belleza, inmortalizada en el cuadro de Boticelli "El nacimiento de Venus", se destruye desde la primera estrofa. En vez de nacer de la belleza del mar Mediterráneo, la diosa sale de una tina de baño, su cabeza de mujer tiene una cabellera tremendamente untuosa. Siguen el cuello grasoso, los omóplatos que sobresalen, la espalda que entra y sale, las redondeces de los riñones, la columna vertebral es rojiza y, al fin, la Clara Venus tiene una tremenda úlcera en el ano.

Es la destrucción de la belleza, la corrupción de lo hermoso, lo grotesco en vez de la gracia y la delicadeza. Sólo faltó el nombre reservado a Nicanor Parra: la antipoesía.

Parra prolonga esta antipoesía. Más preciso, prolonga una tradición antipoética encabezada por Víctor Hugo, Baudelaire y Rimbaud. No hay ninguna ruptura con la tradición. La antipoesía parriana es tradicional. La preceden casi dos siglos. Paradójicamente, la antitradición está en los poemas y no en los antipoemas. Aquellos se alzan contra lo novedoso del feísmo, y al destacar la belleza resultan antitradicionales. Ya decíamos que conviene revisar las afirmaciones fáciles, frecuentemente erróneas.

Conviene señalar que el feísmo, afianzado por Víctor Hugo, tiene antecedentes clarísimos en la literatura clásica española. Los nombres de Francisco Quevedo y de Juan Ruiz (Arcipreste de Hita) vienen de inmediato a la memoria. Terminamos esta evocación con un soneto de Quevedo: 


\section{A Apolo siguiendo a DAFNe}

Bermejazo platero de las cumbres, a cuya luz se espulga la canalla, la ninfa Dafne, que se afufa y calla, si la quieres gozar, paga y no alumbres.

Si quieres ahorrar de pesadumbres, ojo del cielo, trata de compralla: en confites gastó Marte la malla, y la espada en pasteles y en azumbres.

Volvióse en bolsa Júpiter severo; levantóse las faldas la doncella por recogerle en lluvia de dinero:

astucia fue de alguna dueña estrella; que de estrellas sin dueñas no lo infiero; Febo, pues eres Sol, sírvete de ella. (1999: 18)

Es del caso recordar que en el excelente libro de Umberto Eco Historia de la belleza (2010: 300 y siguientes), el autor habla de belleza y melancolía, de lo grotesco y la ironía, de la vaguedad y la revuelta. Así lo bello en el Romanticismo se une y hasta se identifica con categorías claramente negativas. Y aunque pueda parecer increíble, tales categorías negativas se dan en los libros primeros de Rubén Darío, como Abrojos y Otoñales, textos que Parra leyó con especial interés hacia los años 50.

¿Por qué no dar el nombre de antipoemas a los textos de Baudelaire, Rimbaud y Quevedo antes transcritos? Ironía, destrucción de mitos, groserías, burlas están a la vista. La historia esperaba la aparición a mediados del siglo XX de Nicanor Parra. Su poesía y su antipoesía, que tan bien empalma con los Quevedo y Rimbaud, vinieron simplemente a bautizar unas creaturas centenarias varias veces. Y más tradicionales resultan paradójicamente los antipoemas que muchos de los poemas, porque éstos en calidad y cantidad son quizás menos representativos de la lírica contemporánea.

\section{REFERENCIAS}

Baudelaire, Ch. (1961). Las flores del mal. Paris: Garnier Frères. 
Darío, R. (1971). Abrojos, Otoñales, Epístola a la señora de Lugones. En: Obras completas. Madrid: Aguilar (2 vols.).

Eco, U. (2010). Historia de la belleza. Florencia: Debolsillo.

Hugo, V. (1971). Manifiesto romántico. Barcelona: Ediciones Península.

Parra, N. (1937). Cancionero sin nombre. Santiago: Nascimento.

(1954). Poemas y antipoemas. Santiago: Nascimento.

(2006). Obras completas, 2 tomos. Barcelona: Círculo de Lectores, Galaxia Gutenberg.

Quevedo, F. de (1999). Obra poética, tomo II. Madrid: Castalia.

Rimbaud, A. (1980). Rimbaud Obra completa. Barcelona: Libros Río Nuevo. 